\title{
TRANSMISSÃO, CONSERVAÇÃO E DIFUSÃO DA CULTURA NO RIO DE JANEIRO (1808-1821).
}

\author{
MARIA BEATRIZ NIZZA DA SILVA
}

do Departamento de História da Faculdade de Filosofia, Letras e Ciências Humanas da Universidade de São Paulo.

"Much more of the culture native to any given group is the product not of that living population but of its preceding generations".

(Kroeber, The Nature of Culture).

\section{AULAS, COLEGIOS E ACADEMIAS.}

Em qualquer sociedade se observam formas de transmissão cultural de umas gerações para as outras e o que varia é apenas o modo como essa transmissão é feita (oral ou escrito) e aquilo que cada sociedade encara como digno de ser transmitido. Donde resulta que existe sempre, seja em que sociedade for, uma noção mais ou menos consciente das normas, dos valores, dos conhecimentos que as velhas gerações devem transmitir às novas.

Mas enquanto numa sociedade dita primitiva a cultura é algo que diz respeito a todos os seus membros (com distinção apenas dos sexos), nas sociedades ditas civilizadas não só se põe o problema de saber $o$ que é transmitido, mas tambem a quem é transmitido.

Usando a metáfora das "luzes", José da Silva Lisboa, em Observações sobre a prosperidade do Estado, no capítulo sobre a instrução, começa por relacionar cultura e política. Primeiro ao nivel das relações entre as várias nações:

"As nações e governos de mais luzes sempre exerceram real supremacia, ou decisiva preponderância e influência, sobre os outros Estados menos ilustrados" (p. 72). 
Ou por outras palavras, um: Estado é tanto mais poderoso quanto mais ilustrado for. $\mathrm{E}$ do mesmo modo que existe uma relação direta entre o poder das nações e as suas luzes, tambem se constata uma relação direta entre a instrução e a ordem política interna:

"As luzes das ciências, dirigindo todas as artes e indústrias, e mostrando as naturais relações da sociedade, estábelecem a boa ordem civil, e não só dẩo esplendor, mas também o sustento dos impérios".

Ou por outras palavras," as luzes levam os homens a aceitar

"as naturais relações da sociedade" (ou seja, a divisão do trabalho e a hierarquia daqui resultante), mantendo assim "a boa ordem civil".

Em apoio desta última tese, Silva Lisboa recorre a um texto de Adam Smith, mas não só alterando-o ao traduzi-lo, como retirando-o do seu contexto que era precisamente a discussão do problema da instrução de todas as classes inferiores do povo. Isolando o texto, Silva Lisboa apresenta a passagem de Adam Smith como referente ao povo em geral. Trata-se de uma forma tão flagrante de distorsão ideológica que não resistimos a colocar lado a lado o original e a sua versão portuguesa:

An Inquiry into the nature and causes of the wealth of nations, Liv. V, cap. I

An instructed and intelligent people; besides, are always more decent and orderly than an ignorant and stupid one. They feel themselves, each individually, more respectable and more likely to obtain the respect of their lawful superiors, and they are therefore more disposed to respect those superiors. They are more disposed to examine, and more capable of seeing through, the interested complaints of faction and sedition, and they are, upon that account, less apt : to be misled into any wanton or unnecessary opposition to the measures of
Versão portuguesa

Um povo instruído é sempre mais obediente e morigerado, do que um ignorante e estúpido. Quanto ele tem mais luzes, tanto é menos exposto às ilusões do entusiasmo e superstição, e tanto é mais capaz de ver as queixas interessadas da facção e sedição, e năo se precipita a fatos de insubordinação e revolta. Ele sente que é mais respeitável, e portanto é também mais disposto a respeitar aos seus legítimos superiores, e adquire hábitos de ordem, e virtudes morais e políticas. A segurança do governo depende muito do favorável juizo e confiança, 
government. In free countries, where the safety of government depends very much upon the favourable judgement which the people may form of its conduct, it must surely be of the highest importance that they should not be disposed to judge rashly or capriciously concerning it". que $o$ povo tem na sua administração; e é da maior importância, que tenha luzes para não julgar temerária, ou caprichosamente.

Lendo o original e a tradução de José da Silva Lisboà, vemos que importava ao tradutor apoiar-se na autoridade de Adam Smith, mas transferindo o problema da instrução de "all inferior ranks of people" numa monarquia constitucional (Smith usa a expressão "free countries"), para a questão menos perigosa da instrução do "povo" em geral nos quadros do Antigo Regime.

E através dos textos elogiosos das medidas governamentais a favor da difusão das luzes no Brasil percebe-se perfeitamente que grupos eram abarcados por esse termo povo:

"S. A. R. não só tem mantido os estudos públicos de Belas Letras, e da Filosofia, que haviam no Brasil; mas já ordenou o estabelecimento de outros de alta literatura, para o ensino das Ciênciäs Matemáticas, e por um plano (que logo virá à luz) talvez o mais vasto, e o mais bem harmoniado, de instrução pública, em todas as repartições da Milícia e Marinha, que nos são de necessidade imediata. Igualmente estabeleceu Aulas de Comércio, e Curativo; e tem manifestado ainda maiores destinos de dar livre carreira, e especial proteção a todas as doutrinas úteis, mandando vir do reino escolhida livraria das ciências exatas, e um observatório astronômico, contendo o magnífico telescópio do celebrado inglês Herschell" (p. 75).

O Estado se preocupava fundamentalmente com a formação de quadros dirigentes na Administração e Exército, com a proteção aos estudos destinados ao Comércio e à Arte de curar e portanto fica claro o sentido restrito do vocábulo povo, quando Silva Lisboa o emprega na seguinte frase:

"O povo louva afetuosamente a seu príncipe, que assim lhe faz ver prodígios da natureza, e invenções dos homens; de que antes nem tinha ideia". 
Eram apenas 10 os professores régios no Rio de Janeiro, segundo a informação dos Almanaques de 1816 e 1817: 3 de Gramática Latina (com 3 substitutos), um de Língua grega, outro de Retórica, outro de Filosofia e finalmente outro de Desenho e Figura. Mas este número talvez não fosse exato, pois não refere a cadeira de Aritmética, Álgebra e Trigonometria, cujo programa foi tão minuciosamente traçado pela Mesa do Desembargo do Paço a 14 de julho de 1809:

"Este professor ensinará o cálculo numérico provisoriamente com o algébrico, tanto das quantidades inteiras como fracionárias; a resolução das equações algébricas do $1^{\circ}$ e $2^{9}$ grau; a formação das potências, e extração das suas raízes; a teoria das proporções, e progressões; as regras de três simples e composta, direta e inversa; as de sociedade, de liga e falsa posição, terminando o ensino da Aritmética e Álgebra com a resolução dos diferentes problemas de mais uso no Comércio, como são os que pertencem a juros, ou interesses, etc., e com a explicação do uso das tábuas de Price, insertas no tratado das pensões vitalícias de Saint Cirau, publicadas já em português. No ensino da Geometria teórica procurará acostumar o entendimento dos seus discípulos a sentir a evidência dos raciocínios, a apreciar a exatidão, é a pensar metodicamente. Mostrará sucessivamente o uso e aplicação de todas as proposições de Geometria, de que se pode tirar vantagens nas diferentes artes e ofícios, na medida das distâncias, superfícies, e volumes, expondo o método de por em prática as operações geométricas. Passará depois à Trigonometria plana, e à descrição e uso dos instrumentos nas diversas operações geodésicas, como são grafómetros, planchetas, etc., (1) dando no fim de cada ano letivo alguns dias de exercícios práticos no uso dos instrumentos, e na medida das distâncias, etc.".

Os sublinhados são nossos e destinam-se a chamar a atenção por um lado para o caráter propedêutico da Geometria teórica, que ensinava a pensar metodicamente e a apreciar a exatidão dos raciocínios, e por outro lado para as aplicações práticas das matérias ensinadas, quer no Comércio, quer nas Artes e Ofícios.

A Mesa do Desembargo do Paço tambem programou minuciosamente o ensino das cadeiras de Língua inglesa e francesa:

(1) . - Segundo a definição de Morais e Silva no seu Dicionário, grafómetro era um instrumento matemático, "um semicírculo graduado, com sua alidada, e suas pínulas" e servia para "tirar planos, medir ângulos, etc.". Quanto à plancheta ou prancheta era um "instrumento matemático de medir distâncias, usado no cartear geográfico". 


\begin{abstract}
"No ensino das duas línguas referidas seguirão os professores, quanto ao tempo, e horas das liçōes, e atestações do aproveitamento dos discípulos, o mesmo que se acha estabelecido, e praticado pelos professores de Gramática latina. E pelo que toca à matéria do ensino, ditarão as suas lições pela gramática que for mais bem conceituada, enquanto não formalizarem alguma de sua composição, habilitando os discípulos na pronunciação das expressões, e das vozes das respetivas línguas, adestrando-os em bem falar e escrever, servindo-se dos melhores modelos do século de Luís XIV, e fazendo que nas traduções dos lugares conheçam o gênio, e idiotismo da língua, e as belezas e elegância dela, e do estilo e gosto mais apurado e seguido. Na escolha destes livros se preferirão os da mais perfeita e exata moral; e para a comparação com a língua pátria se escolherão os autores clássicos do século de quinhentos, que melhor reputação têm entre os nossos literatos".
\end{abstract} talhada.

Este texto é tão rico de significações que exige uma análise de-

O ensino de uma língua estrangeira começava pelo estudo da sua gramática, mas esta por si só não era considerada suficiente: importava recorrer ao estudo dos clássicos dessas línguas. Para o francês, os modelos eram os autores do século de Luís XIV, mas o texto não nos diz a que época pertenciam os modelos ingleses. O estudo dos clássicos estrangeiros exigia a comparação com os clássicos portugueses e estes, para a Mesa do Desembargo do Paço, eram os autores do século XVI. Tudo se passa como se as duas línguas, francês e português, tivessem atingido o seu clímax de perfeição no passado e os autores contemporâneos não tivessem outro recurso senão copiar tais modelos. Os burocratas do Desembargo do Paço tinham consciência da especificidade estrutural de cada língua e portanto insistem que se ensine aos alunos a conhecer "o gênio e o idiotismo" da língua estrangeira, sem o que não haveria uma boa tradução. Há a noção de que cada língua possui os seus próprios recursos estilísticos e que o mais dificil de ensinar aos alunos de uma língua estrangeira é precisamente a maneira de adquirirem um "estilo" nesse idioma (2). Não só o aluno devia ser posto em contacto com os clássicos da língua a ser aprendida, como o pro-

(2). - E interessante notar como o burocrata da Mesa do Desembargo do Paço está próximo das modernas concepçôes do ensino de uma língua estrangeira: "One major problem $(\ldots)$ in the teaching of a foreign language is giving the student a sense of style". escreve Nils Erik Enkvist, no ensaio "On defining style - An essay in aplied Linguistics", in Linguistics and Style, Londres, 1971, p. 6. 
fessor tinha de proceder a uma triagem destes, de maneira a só utilizar aqueles autores que fossem "da mais perfeita e exata moral". Jamais o pretexto de estudos de línguas podia servir de desculpa para a leitura de obras condenáveis, embora modelares do ponto de vista da linguagem.

A criação de cadeiras públicas isoladas não constituia contudo a preocupação básica do governo em matéria de transmissão de cultura: o papel do Estado nesta área concentrou-se na preparação de oficiais e de cirurgiões, através de Academias como as dos Guardas Marinha e a Academia Militar, e dos Estudos Médico-cirúrgicos, instituições essas que passamos a estudar, mais do ponto de vista das disciplinas lecionadas do que da sua organização interna.

Quanto à primeira Academia (cuja biblioteca estudaremos no capítulo seguinte pois encontramos o seu catálogo manuscrito na $\mathrm{Bi}$ blioteca Nacional), sabemos que nela se estudavam as Matemáticas, as Ciências físico-matemáticas, a Artilharia, a Navegação, o Desenho. O curso completo durava 3 anos apenas, enquanto o curso completo da Academia Militar durava 7. No primeiro ano estudava-se Aritmética, Álgebra até às equações de 2 o grau, a Geometria e a Trigonometria por Bezout; no segundo; a Álgebra, a aplicação da Álgebra à Geometria, o Cálculo diferencial e integral, e a Mecânica, tambem por Bezout; no terceiro, a Ótica e a Astronomia pelos textos de La Caille, a Navegação, o Aparelho Náutico e a Prática dos instrumentos. Recebiam os alunos tambem aulas de Artilharia, pelo compêndio de Muller (3), e em todos os anos havia aulas de Desenho (Balbi, Essai statistique, t. II, p. 59, nota 1). Os alunos tinham ainda aulas práticas de exercícios com fuzil, canhão, morteiro e obus, lições de esgrima e de manobra naval. Apesar de todas estas atividades, eram apenas 7 os professores: um para o primeiro ano, outro para o segundo, dois para o terceiro, um professor de Desenho e o seu substituto, e um professor de aparelho. Além destes havia um instrutor para os exercícios militares e um mestre de esgrima. A média de alunos era 40 apenas, sendo ainda admitidos na Academia indivíduos que se destinavam à pilotagem e que por este motivo cursavam apenas as matérias do primeiro e do terceiro ano, sem estarem obrigados aos exercícios militares. De acordo com a decisão de 6 de março de 1809 , nos exames para habilitação dos 1 's Pilotos, examinava-se

(3). - Contudo esta obra de John Muller, intitulada A Treatise of Artillery ... to which is prefixed an introduction, with a theory of powder applied to fire-arms não consta do catálogo da biblioteca. 
:." "não só de Pilotagem propriamente tal, mas também de Manobra", porque aos candidatos se confiava "a riqueza do comércio nacional $\mathrm{e}$ as vidas de muitas equipagens".

Quer dizer portanto que a profissão de Piloto, embora exigisse menos cultura científica do que a de um oficial de Marinha, não era totalmente destituida de uma base erudita e livresca, pois, como veremos na análise da biblioteca da Academia, a bibliografia sobre Pilotagem e Manobra era assaz vasta.

Numa sociedade como a do Rio de Janeiro no início do século passado, em que existia uma elite cultural constituida fundamentalmente por nobres, empregados públicos, militares (de terra ou de mar) e alguns empregados de comércio, não podemos deixar de considerar, um pouco mais atentamente do que habitualmente o fazem os historiadores da cultura, a instituição destinada a transmitir os conhecimentos científicos considerados indispensáveis à carreira das armas. Não só a "arte da guerra" ou "ciência militar" constituia uma área do saber tão importante como qualquer outra, exigindo mesmo um elevado número de ciências auxiliares, mas tambem, no panorama científico de então, o militar possuia um estatuto cultural semelhante ao do bacharel, por exemplo, ou ao do cirurgião.

Em 1809, mesmo antes de se abrirem as aulas da Academia Militar, foi nomeado lente da cadeira de língua inglesa desta Academia Eduardo Tomás Cohill com a graduação de $2^{\circ}$ Tenente de Artilharia e o soldo de $12 \$ 000$ reis por mes (Decreto de 30 de maio de 1809). A carta régia de 4 de dezembro de 1810 deu os estatutos à Academia Militar do Rio de Janeiro, dirigida por uma Junta Militar, cujos membros não recebiam um ordenado fixo, mas apenas ajudas de custo para as despesas, "por ser este serviço todo de honra".

Cada membro da Junta tinha uma função própria. Ao Presidente pertencia "a direção dos estudos de Mineralogia, Química, e Física"; ao Deputado Diretor do Arquivo Militar "a direção e assistência dos trabalhos geodésicos" nos quais se deveria seguir o modelo dos trabalhos de Le Roy em Inglaterra e de Delambre em França; o segundo deputado controlaria a disciplina das aulas e de toda a Academia; o terceiro deputado seria destinado ao "traçamento de algum polígono militar" que se construisse no campo "para mostrar o ataque, e a defensa das praças aos alunos"; e à assistência dos exercícios de Artilharia, "tanto de peça, como de morteiro, e de minas"; o quarto deputado assistiria ao "reconhecimento de terrenos, e às manobras de Tática" que fossem propostas para defender ou atacar, e este trabalho seria sempre acompanhado de cartas militares, levantadas pelos alu- 
nos "sem instrụmentos, e por meio prático, mas deduzidos de grandes princípios teóricos".

A Academia, segundo estes estatutos, deveria ter 11 professores e 5 substitutos e a junta, se o julgasse necessário, podia propor professores de língua francesa, inglesa e alemã.

\footnotetext{
"Será obrigação dos professores substituirem-se uns aos outros, quando suceda não bastarem os substitutos, de maneira que jamais se dê o caso de haver cadeiras, que deixem de ser servidas, havendo alunos que possam ouvir as lições".
}

Quando se instalasse uma biblioteca na Academia, haveria um lente de História Militar, que serviria de bibliotecário, e que no oitavo ano do curso explicaria

\footnotetext{
"a História Militar de todos os povos, os progressos que na mesma fez cada nação, e dando uma idéia dos maiores generais nacionais e estrangeiros", devendo explicar ainda "os planos das mais célebres batalhas".
}

Os professores deveriam ser de preferência "oficiais de distintas luzes", mas, na falta destes, poderiam ser escolhidas pessoas que, "ganhando prêmios, e havendo publicado Memórias de conhecido merecimento", se fizessem dignas de serem nomeadas para "lugares de tanta consideração". Os professores podiam requerer a sua jubilação ao fim de 20 anos de exercício na cadeira e o seu ordenado anual era de $400 \$ 000$ reis, além do soldo da sua patente; os substitutos ganhavam $200 \$ 000$ reis. A importância atribuida pelo Estado à elaboração dos compêndios era tão grande que nenhum lente poderia ser adiantado de posto ou receber recompensas sem ter elaborado um.

Os alunos da Academia foram agrupados em duas grandes classes: a dos obrigados e a dos voluntários. Mas todos passavam pelo mesmo tipo de exame de admissão: deviam saber as quatro primeiras operações! Isto aos 15 anos, que era a idade mínima exigida. Lugar de honra nas aulas seria dado aos que conhecessem latim e grego e línguas vivas.

Os alunos "obrigados", ao mesmo tempo que frequentavam a Academia, ingressavam na carreira militar, assentando logo praça de soldados e cadetes de Artilharia, vencendo uns e outros "o soldo e farinha" de sargentos daquela arma. Só estes alunos podiam concorrer aos "partidos" que o Estado mandava estabelecer a favor daqueles 
que mais se distinguissem nos estudos de cada ano, excetuado o primeiro. Havia 3 "partidos": um de 20 moedas de oiro de $4 \$ 800$ reis cada uma; outro de 15 e outro de 10 . E ainda 3 prêmios de $250 \$ 000$ reis cada um a quem apresentasse "uma melhor e mais profícua $\mathrm{Me}$ mória com alguma descoberta, ou util aplicação em cada uma das ciências". Os alunos "obrigados", alem dos estudos teóricos e práticos, prestavam serviço no Regimento de Artilharia e no fim do $5^{\circ}$ ano eram já nomeados oficiais pelo governante, sendo encaminhados pela Junta Militar para as várias armas, conforme "os talentos, o gosto e a aplicação de cada um".

Muito embora o curso da Academia Militar tivesse a duração de 7 anos, nem todos os alunos eram forçados a estudar durante todo este período; só os oficiais Engenheiros e de Artilharia, pois estas armas exigiam estudos mais complexos do que a Infantaria ou Cavalaria, que só necessitavam do primeiro ano do curso matemático e do primeiro ano do curso militar (4). Contudo seguir o curso completo apresentava vantagens: dava preferência nas promoções e possibilitava a ascensão a general, posto este que nenhum oficial podia alcançar sem estudos completos, a menos que tivesse dado "demonstrações de heróico valor".

A participação do Estado na transmissão da cultura científica faz-se sentir ainda numa outra área fundamental: a da Medicina. Logo depois da chegada da corte ao Rio de Janeiro, o decreto de 2 de abril de 1808 nomeou Joaquim da Rocha Mazarem para lente da nova cadeira de Anatomia e o de 12 de abril de 1809 estabeleceu uma cadeira de Medicina Clínica, teórica e prática, no Hospital Militar. Como a maior parte dos decretos, este último obedece a uma estrutura tripartida que passamos a analisar, devido à sua importância cultural: enunciado das razões, enunciado do objetivo e finalmente a medido tomada.

Enunciado das razões: o texto refere a absoluta e instante necessidade de haver cirurgiões com "princípios de Medicina", que tratassem mais convenientemente os doentes a bordo das naus e os povos das distantes povoações do vasto continente do Brasil. Por outras palavras, não havendo médicos em número suficiente, era necessário que os cirurgiōes adquirissem um saber que normalmente não era exigido na sua profissão. No Brasil o cirurgião tinha de se improvisar médico e daí o fato de se exigir dele o conhecimento dos "princípios de Medicina", mais complexos.

(4). - A preparação de oficiais engenheiros requeria principalmente maior número de aulas de Desenho e por isso o texto dos Estatutos estabelecia: "nos quatro primeiros anos desenharão figura e paysage, e nos três militares os desenhos relativos às matérias de cada um dos anos". 
Enunciado do objetivo:

"ensinar os princípios elementares da Matéria Médica e Farmacêutica, dando igualmente um plano de Polícia Médica, de Higiene geral e particular e de Terapêutica".

E finalmente a medida tomada pelo governante, levado pelas razões acima mencionadas e com o objetivo descrito: criação da cadeira de Medicina Clínica, teórica e prática, e nomeação para ela do Dr. José Maria Bomtempo.

A análise deste documento revela-nos algo de muito importante para o conhecimento da cultura científica da época: a Cirurgia como atividade claramente distinta da Medicina. E revela-nos tambem, por outro lado, a atenuação dessa distinção devido à situação especial do Brasil. Na cultura europeia, quer social quer culturalmente, o cirurgião era inferior ao médico (tendo mesmo, nos séculos XVII e XVIII, sido agrupado corporativamente com os barbeiros) e só atuava nas chamadas "doenças cirúrgicas". A necessidade de médicos no Brasil não permitia uma hierarquia rígida e temos aqui um exemplo bem claro de algo que os historiadores da cultura tem sempre grande dificuldade em mostrar concretamente: o processo de adaptação de uma forina de cultura a um novo meio. Sendo a cultura de uma sociedade constituida por numerosos elementos, o que realmente interessa fazer em história da cultura não é referir muito vagamente o princípio de adaptação das culturas, mas sim mostrar concretamente que elementos sofrem essa adaptação. Neste caso temos o abaixamento do nivel médico, ou melhor, o alargamento da área cirúrgica.

Se analisarmos o Regimento da Fisicatura-mor vemos que o $\S$ XXI estabelecia que nas cidades e vilas populosas haveria número certo de cirurgiōes aprovados, que tratassem aqueles doentes de enfermidades internas que não pudessem ser assistidos por médicos. Mas para serem providos pelo Físico-Mor, precisavam os cirurgiões de passar pelos "exames de oposição", que versariam, conforme o § XXII.

"sobre o conhecimento e cura das enfermidades agudas e crônicas, o prognóstico, e medicamentos indicados, assim como o mođó de fazer uma consulta a qualquer médico, e de inquirir um enfermo".

O exame seria feito por dois médicos e pelo Juíz Comissário presidente, 
"atendendo-se sempre nas perguntas aos poucos conhecimentos que os cirurgiões podem ter".

Mas podia até acontecer que num determinado lugar do Brasil não houvesse médico nem boticário, e neste caso o cirurgião teria tambem de se submeter a exame de farmácia, o qual deveria

\footnotetext{
"ser moderado, e versar somente sobre as preparações mais gerais" ( $\$$ XXIV).
}

Não tanto na Corte, mas nas demais regiões do Brasil, a falta de médicos, e mesmo de cirurgiões e boticários, fazia-se sentir de tal modo que o Regimento da Fisicatura-Mor previa a legalização dos curadores:

"Os que não sendo cirurgiões se tiverem aplicado ao estudo da Medicina, e observação dos medicamentos do país, e que forem julgados necessários nos lugares remotos onde não há nem pode haver médico, nem boticário, nem cirurgiōes, que bastem segundo a população, o Juíz Comissário com o seu Escrivão, e unicamente com um médico, os examinará de Medicina e Farmácia, segundo os seus poucos conhecimentos, e thes passará licença anual de curadores" ( $\$ \mathrm{XXV}$ ).

A situação brasileira exigia portanto a rápida criação de um curso de Cirurgia, de preferência ao de Medicina, mais complexo. O decreto de 1 de abril de 1813, aprovando o plano de estudos de Cirurgia no Hospital da Misericórdia do Rio de Janeiro, elaborado por Manuel Luís Álvares de Carvalho, revela claramente o nivel de estudos que o governo joanino achava conveniente por em prática no Brasil.

O curso era de 5 anos e apenas se exigia dos futuros cirurgiōes que ao ingressarem soubessem "ler e escrever corretamente". O conhecimento do francês e do inglês poderia ser adquirido no decorrer do curso, sendo os exames destas línguas feitos antes das matrículas no $2^{\circ}$ e $3^{\circ}$ ano, respectivamente. O nivel era tão baixo que aqueles que soubessem latim ou geometria se podiam matricular diretamente no $2^{\circ}$ ano, pois o conhecimento de tais matérias era sinal de que os seus cérebros estavam mais desenvolvidos.

O curriculum era o seguinte:

19 ano: Anatomia; Química, Farmacêutica e "o conhecimento dos gêneros necessários à Matéria Médica e Cirúrgica sem 
aplicações". Os alunos assistiam ao curativo no Hospital.

29 ano: "Explicação das entranhas, e das partes mais necessárias à vida humana, isto é, a Fisiologia".

$3^{\circ}$ ano: Liçōes de Higiene, Etiologia, Patologia, Terapêutica, dadas por um médico.

49 ano: Instruções cirúrgicas e operações, e lições de Arte obstetrícia.

5\% ano: Prática de Medicina.

No fim deste último ano, os alunos recebiam carta de aprovados em Cirurgia, mas se frequentassem de novo o $4^{\circ}$ e $5^{\circ}$ ano, recebiam a graduação de formados em Cirurgia, o que significa que o próprio Estado reconhecia como insuficiente o saber prático adquirido durante aquele período e procurava incentivar a aquisição de uma maior prática, não através de novos cursos, mas com a repetição dos já feitos. E este plano acenava com uma graduação em Medicina, sem contudo indicar como ela podia efetivamente ser obtida. Os termos em que a questão é levantada são por demais vagos:

"Poderão todos aqueles que se enriquecerem de princípios e prática, a ponto de fazerem os exames, que aos médicos se determinam, chegar a ter a formatura, e o grau de doutor em Medicina".

Este foi o plano de estudos aprovado e adotado pelo decreto de 1813, mas, um ano antes, a Impressão Régia do Rio de Janeiro publicara um outro plano, da autoria do médico da Câmara, Vicente Navarro de Andrade. Mais amplo, pois previa a formação simultânea de médicos, cirurgiões e boticários, bem fundamentado do ponto de vista da teoria médica da época, o plano de Navarro de Andrade não foi contudo posto em prática. Antes de tentar descobrir por que razões o governo não preferiu este projeto, convém comparar os dois, apenas ao nivel do curso cirúrgico, que foi o efetivado.

Plano de 1812

Para a matrícula no $1^{\circ}$ ano de $\mathrm{Ci}$ rurgia exigia certidão de aprovação em Latim e Filosofia Racional e Moral

Duração do curso: 5 anos

Matérias:

19 ano: Anatomia e Fisiologia

$2^{\circ}$ ano: Patologia geral, Terapêuti-
Plano de 1813 (aprovado)

Exigia que os alunos soubessem ler e escrever

Duração do curso: 5 anos

Matérias:

19 Anatomia, Química, Farmacêutica

$2 \circ$ Fisiologia

$3^{\circ}$ Higiene, Etiologia, Patologia, Tepêutica 
ca, Semiótica, Higiene

30 ano: Explicação dos Sistemas de

História Natural, Botânica Médica, e

Farmácia

4 ano: Patologia especial cirúrgica, Operações cirúrgicas e Arte obstetrícia

59 ano: Clínica cirúrgica.

O plano aprovado não apresenta qualquer justificação teórica para a distribuição das matérias no curriculum, ao passo que Navarro de Andrade justifica a maneira como as disciplinas deviam ser ministradas. Por exemplo, a necessidade de a Anatomia ser acompanhada da Fisiologia, matéria que o plano oficial deslocou para o $2^{\circ}$ ano:

"E conveniente que se ensinem simultaneamente, não só porque o estudo anatômico, separado do fisiológico é árido, e por si mesmo desagradável, mas também, porque tratando da Fisiologia separadamente, é sempre mister que na explicação das funções da economia animal, preceda em resumo a descrição das partes instrumentais de cada uma delas" (p. 30).

Apoiando-se nos "fisiologistas modernos", e principalmente nos ensinamentos de Vicq d'Azir, cujas obras publicadas em 1805 ele conhecia, Navarro de Andrade mostrava de que maneira a ligação íntima entre a Anatomia e a Fisiologia podia ser exposta aos estudantes:

"ou fazendo quadrar a cada uma das partes anatômicas os conhecimentos fisiológicos, de que elas são órgãos, ou estabelecendo uma divisão geral das funções, e no tratado de cada uma delas, descrever competentemente as partes do corpo humano que lhe são relativas" (p. 31 ).

Sendo a Fisiologia "o conhecimento das funções da economia animal no estado de saúde", o seu estudo devia necessariamente preceder o da Patologia, ou seja, "o conhecimento das afeções morbosas". Se a Terapêutica é a arte de restabelecer a saúde, a Higiene ou arte de a conservar deve constituir um estudo paralelo, e isso o plano oficial tambem reconhecia. O que não faz sentido, dentro do sistema do saber médico da época, é colocar o estudo da Farmacêutica (ou Farmácia, na terminologia de Navarro de Andrade), logo no $1^{\text {o }}$ ano, antes da Terapêutica, mas esta opção do plano oficial tem uma justificação prática, se não teórica. Havia urgência, no contexto da sociedade ca- 
rioca e principalmente da sociedade brasileira em geral, de um conhecimento imediato dos remédios mais comuns, e daí a inclusão no $1^{9}$ ano não só da Farmacêutica como da Química, pois muitos dos medicamentos então usados implicavam manipulações químicas. Navarro de Andrade, menos preocupado com as necessidades práticas, agrupou a Farmácia com o estudo das disciplinas consideradas básicas para o seu estudo: Sistema de História Natural e Botânica médica.

Uma diferença substancial aparece entre as matérias do $5^{\circ}$ ano, não só ao nivel da nomenclatura, mas tambem ao nivel do conteudo: Navarro de Andrade fala de Clínica cirúrgica; o plano oficial de Prática Médica. O que significa esta diferença?

Em primeiro lugar, Navarro de Andrade, uma vez que propunha um sistema geral que formava médicos tambem, no curso cirúrgico mantém-se dentro das disciplinas propriamente cirúrgicas, ao passo que o plano oficial, que se preocupava apenas com a formação de cirurgiões, queria dar a estes alguns princípios de Medicina.

Em segundo lugar temos o uso do termo Clínica por Navarro de Andrade, cuja noção, segundo mostrou Michel Foucault em La naissance de la clinique, era em 1812 algo de recente no saber médico. Ora o médico portugues detém-se precisamente na análise desta noção:

\footnotetext{
"No leito do enfermo a natureza dá o texto das explicações médicas, e aí se confirmam os dogmas da teoria. A inspeção dos diversos doentes, o exame do seu padecer, e a fisionomia particular das enfermidades em diferentes períodos, a observação dos sintomas, e o exame da relação que eles têm com o estado da economia animal, manifestado pela terminação da moléstia na saúde ou na morte, são coisas de tanta vantagem que nada pode supri-las" (p. 36).
}

A Clínica, ou seja etimologicamente a observação do doente acamado, implicava, como acentua Foucault, uma organização hospitalar diversa daquela que existia então no Rio de Janeiro, se excetuarmos os Hospitais Regimentais criados já em 1820. Navarro de Andrade refere igualmente este ponto no seu plano:

"Para que este método seja mais proveitoso, e se dê a devida atenção a cada enfermo, devem haver enfermarias particulares, destinadas ao ensino, nas quais se tratem somente aqueles doentes que o professor escolher entre os do hospital, ficando os outros ao cuidado dos médicos da casa. E como quer que não baste a obser- 
vação sobre o tratamento dos homens, e que seja necessária a prática dos partos, o Hospital da Misericórdia concorrerá com uma enfermaria médica e cirúrgica, aonde os lentes de Prática tratarão das enfermas que escolherem para objeto de suas lições" (p. 36-7) .

Resta agora formular a pergunta: por que não foi escolhido o plano de Navarro de Andrade que, além de mais lógico e mais atualizado, resolvia simultâneamente o problema da falta de médicos com a criação de apenas três disciplinas a mais no curriculum médico, a saber, Medicina legal, História da Medicina e Nosologia? Cremos que as razões são exclusivamente sociais, de conservação dos privilégios da restrita classe médica em relação aos cirurgiões. Apesar de médico, Navarro de Andrade mostra a este respeito uma abertura pouco comum. Depois de referir que os franceses só depois da revolução aboliram os preconceitos que rodeavam a Medicina e a Cirurgia, escreve:

"Nada havia com efeito mais injusto do que a diferença de consideração pública entre os membros de repartições igualmente difíceis, e igualmente úteis pelo seu objeto. Estas duas partes da arte de curar têm tanta relação entre si, que não pode alcançar-se um conhecimento pleno de cada uma delas, ignorando-se os elementos da outra" (p. 20-1).

Contudo os preconceitos eram dificeis de extirpar, e no início do século XIX o ramo da Medicina era, "ainda que indevidamente", mais considerado na sociedade portuguesa,

"recaindo assim como dantes, a prática da Cirurgia em pessoas que raras vezes estão no caso de merecerem um título, em cuja concessão tem sempre havido uma liberalidade repreensível" (p. 22).

Essa liberalidade acentuou-se com a necessidade de formar rapidamente cirurgióes, e só assim se explica que de um ano para o outro o seu número tenha passado de 25 para 70 (1816 para 1817). Os exames de Cirurgia obedeciam sempre ao mesmo esquema tripartido: havia um ponto de Anatomia, outro de Cirurgia e outro de Operações, ligados por uma unidade temática. Vejamos alguns exemplos tirados dos papéis da Fisicatura-Mor:

1 - Anatomia: O ouvido externo e interno. Cirurgia: As moléstias do ouvido em geral, e em particular, e como se remedeiam. 
Operações:' De que modo se extraem os corpos estranhos do ouvido, e se remedeiam por meio da operação.

2 - Anatomia: Ventrículo, e intestinos, e a ação destas partes nos ingeitos fisiologicamente falando. Cirurgia: Feridas do estômago, e dos intestinos como se curam. Operações: Como se remedeiam as feridas dos intestinos segundo as diversas circunstâncias, e complicações (Caixa 464, Pacote 2).

O interesse do Estado em propagar e apoiar a transmissão da cultura cirúrgica levou-o a criar pensionistás na Academia Médico-Cirúrgica pelo decreto de 16 de dezembro de 1820:

"... querendo eu favorecer a útil aplicação a estudos tão necessários ao bem público, e com o fim de habilitar pessoas que possam depois ser convenientemente empregadas como Cirurgiões nas minhas tropas e nas diversas províncias deste reino, onde haja falta de Professores de Saúde: sou servido estabelecer 12 pensōes de $9 \$ 600$ mensais para 12 alunos da referida Academia, que sejam pobres, de bom procedimento, e que mostrem aptidão para aqueles estudos".

O Estado do Antigo Regime preocupava-se fundamentalmente com a preparação profissional de militares e cirurgiões. Quanto aos empregados públicos, só dos amanuenses e praticantes do Real Erário se exigiam

"os primordiais conhecimentos de cálculo, e método das transações, que têm lugar na arrecadação e fisco real",

e por isso eram obrigados a seguir os estudos da Aula do Comércio e a obter aí carta de aprovação (Decisão-Reino, 6 de maio de 1818).

Para a história da cultura são igualmente significativos os atos e as simples intenções, a prática e a sua expressão teórica, e por esta razão o texto do decreto de 12 de agosto de 1816 se nos afigura extremamente rico. Fala no projeto de

"uma Escola Real de Ciências, Artes e Ofícios, em que se promova e difunda a instrução e conhecimentos indispensáveis aos. homens destinados não só aos empregos públicos de administração do Estado, mas também ao progresso da Agricultura, Mineralogia, Indústria e Comércio, de que resulta a subsistência, comodidade e civilização dos povos, maiormente neste continente, cuja extensão, não tendo ainda o devido e correspondente número de braços indispensáveis ao tamanho e aproveitamento do terreno, precisa dos 
grandes socorros da Estatística, para aproveitar os produtos, cujo valor e preciosidade podem vir a formar do Brasil o mais rico e opulento dos reinos conhecidos; fazendo-se portanto necessário aos habitantes o estudo das Belas Artes com aplicação e referência aos ofícios mecânicos, cuja prática, perfeição e utilidade depende dos conhecimentos teóricos daquelas artes e difusivas luzes das Ciências naturais, físicas e exatas".

Com a prolixidade habitual nos textos burocráticos, este decreto, que afinal de contas estabelece simplesmente as pensões anuais aos componentes da célebre "missão francesa", põe-nos por assim dizer diante da política cultural do governante.

Façamos uma análise de texto. Concebe-se uma Escola de Ciências, Artes e Ofícios, expressão que reflete uma concepção hierárquica do saber, de um saber que vai do mais teórico ao mais prático, e que, ao mesmo tempo, exprime a indissolubilidade dessa três formas de conhecimento, na medida em que cada uma pressupõe as outras. $O$ que aliás fica bem claro na parte final do texto, onde se fala da aplicação das Belas Artes aos ofícios mecânicos e ao mesmo tempo se alude às "difusivas luzes das Ciências naturais, físicas e exatas". Tal escola teria como objetivo formar, não apenas burocratas, mas homens capazes de concorrer para a "subsistência, comodidade e civilização dos povos" e de tirar o máximo partido dos produtos da natureza, pois na concepção da época as nações eram tanto mais civilizadas quanto mais se afastavam de uma simples economia de subsistência.

Pouco importa que o projeto ambicioso dessa Escola Real de Ciências, Artes e Ofícios não se tenha concretizado e que, em sua substituição, fosse criada uma simples Academia de Desenho, Pintura, Escultura e Arquitetura Civil (Dec. de 23 de novembro de 1820). $\mathrm{Na}$ justificativa teórica desta instituição observamos a mesma preocupação que no decreto de 1816 :

"as artes do Desenho, Pintura, Escultura, e Arquitetura civil, são indispensáveis à civilização dos povos, e instrução pública dos meus vassalos, além do aumento que podem dar aos objetos da Indústria, Física, e História natural".

Principiaram então as aulas de Pintura, Desenho, Escultura e Gravura, para as quais foram nomeados os seguintes professores:

"Lente de Desenho, Henrique José da Silva, vencede

$$
\text { ordenado anual }
$$


Secretário da Academia e Escola Real, Luís Rafael

Soyer

$480 \$ \mathrm{rs}$

Lente de Pintura de paisagem, Nicolau Antônio Taunay

$800 \$ \mathrm{rs}$

Dito de Pintura de história, João Batista Debret

$800 \$$ rs

Dito de Escultura, Augusto Taunay

$800 \$ \mathrm{rs}$

Dito de Arquitetura, Augusto Henrique Vitório Frandjean

$800 \$$ rs

Dito de Mecânica, Francisco Ovide

$800 \$ \mathrm{rs}$

Pensionários de Desenho e Pintura, Simplício Rodrigues da Silva, José de Cristo Moreira, Francisco Pedro do Amaral; de Escultura, Marcos Ferrez; de Gravura, Zeferino Ferrez".

Como vemos, a Mecânica era ensinada juntamente com as denominadas Belas Artes, de acordo com a política cultural de preparar artistas não no sentido atual do termo, mas artistas num sentido muito próximo de artesão ou artífice. Aliás esta política aparace claramente no Aviso de 11 de setembro de 1820 :

\footnotetext{
"Constando na augusta presença de el-rei nosso senhor os progressos feitos pelos alunos da nova aula de Desenho estabelecida no Arsenal do Exército, para ensino dos aprendizes do mesmo Arsenal; e atendendo o mesmo senhor ao quanto é necessária esta arte a todos os trabalhos mecânicos: é servido ordenar que na referida aula se admitam ao seu estudo todas as pessoas que dele se quiserem aproveitar, não obstante não serem dos mencionados aprendizes".
}

Na transmissão da cultura há que levar em conta não apenas a iniciativa governamental, mas tambem os planos de educação propostos pela esfera privada. Excetuando o rico material recolhido nos anúncios da Gazeta do Rio de Janeiro, só encontramos um plano de educação entre os documentos do Arquivo Nacional: o do colégio de Joaquim Manuel de Faria, apresentado à Mesa do Desembargo do Paço em 1809.

Dizia o plano que haveria naquela casa de educação "um bom mestre de primeiras letras", em cuja aula se ensinaria "a ler e depois a escrever bem e com acerto a língua nacional", ensinando o mesmo professor a Gramática portuguesa e a ciência de contar, "fazendo conhecer aos discípulos todas as razões por que em qualquer lugar se escreve tal, ou qual algarismo". Haveria um mestre de língua francesa que "gramaticalmente e mesmo por prática" a ensinasse aos discípulos, sendo obrigado em certos dias "a conversar familiarmente com eles em francês". Haveria um mestre de inglês, que ensinaria esta 
língua do mesmo modo, e finalmente um mestre de língua latina para aqueles meninos cujos pais quisessem que a aprendessem, sendo portanto uma disciplina optativa dentro do plano, enquanto o francês e o inglês aparecem como obrigatórios (Caixa 148).

Através de um levantamento exaustivo dos anúncios da Gazeta do Rio de Janeiro vimos existirem neste período no Rio de Janeiro 15 cursos ou Colégios femininos e 19 masculinos. Notamos a separação nítida entre a educação feminina e a educação masculina e começaremos por mostrar o que as meninas aprendiam, através de uma análise simultâneamente quantitativa e qualitativa. Havia 15 aulas diferentes, incluindo os colégios propriamente ditos, e o número de cursos que ensinavam as diferentes matérias era o seguinte:

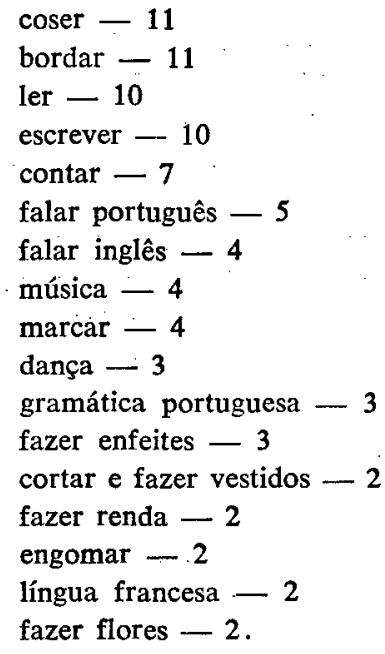

Apenas uma vez encontramos referidas cada uma das seguintes matérias: religião, moral, desenho, gramática francesa, gramática inglesa, tocar, cantar, manejo da casa, fazer toucados, fazer chapéus de palha, fazer meia, lavar filós, lavar chapéus de palha, lavar meias de seda, coser liso, preparar meias de seda e finalmente bons costumes.

Como vemos a sociedade carioca considerava como matérias básicas para a educação feminina saber por um lado ler e escrever, e por outro coser e bordar. Chama a nossa atenção o ensino de técnicas como fazer flores ou toucados, e a transmissão das chamadas prendas sociais, música, dança, canto, desenho. E que as instituições de educação feminina se escalonavam no Rio de Janeiro entre o colégio de luxo 
para meninas e o curso quase artesanal destinado a raparigas, crias e escravas. Basta comparar dois avisos da Gazeta do Rio de Janeiro:

"D. Catarina Jacob toma a liberdade de fazer ciente ao público, que ela tem estabelecido uma academia para instrução de meninas na rua da Lapa, defronte da Exma. Duquesa, em que ensinará a ler, escrever e falar as línguas portuguesa, e inglesa gramaticalmente; toda a qualidade de costura e bordar, e o manejo da casa. Está esperançada que, em consequência do seu cuidado, e atenção na educação, religião, e moral, merecerá eternamente a proteção dos pais, parentes, e pessoas, que lhe confiarem esta honra: cada menina trará cama completa, três toalhas de mão, um talher completo e copo de prata, pagarão por cada menina dezoito mil réis por mês, sendo a quarteis adiantados. Igualmente todas as pessoas, que quiserem, que as suas meninas aprendam música, dança, e desenho, será pago à parte; mandarão todos os sábados os seus criados ao colégio com roupa necessária para se fazer mudança, igualmente as pessoas, que quiserem, mandarão ao sábado de tarde, ou véspera de dia santo, buscar as suas meninas, contanto que às oito horas da noite do mesmo domingo ou dia santo se recolham ao colégio: poderá haver modificação a respeito de famílias, que pela distância de sua habitação lhe seja incômodo, o suprir aos oito dias com roupa e outra alguma cousa; para o que fará particular ajuste. A abertura do colégio deverá ter princípio no primeiro de janeiro de 1813" (1813, n'2).

Muito embora a diretora do colégio se tivesse visto obrigada a baixar os preços do internato de $18 \$ 000$ rs para $12 \$ 000$ rs $\left(1813, \mathrm{n}^{\circ}\right.$ 27), não há dúvida de que se tratava de uma instituição cara, tanto mais que as lições de música, dança, e desenho eram pagas à parte. Ora aprender a ler e escrever, coser e bordar, neste contexto, era muito diferente do aprendizado que as meninas faziam na rua de Matacavalos, com uma senhora que ensinava

"a ler, escrever, e contar, fazer meia, coser, bordar de branco, e de oiro, e prata, e matiz, marcar, fazer flores, enfeites, etc."

e tambem música e canto (1818, no 53 ), e que por outro lado anunciava que na sua casa se fazia toda a qualidade de costura de homem e senhora, se lavava, se engomava de pregas, se lavavam meias de seda $\left(1818, \mathrm{n}^{\circ} 70\right)$. 
Mesmo quando se tratava de um estabelecimento misto, como o que funcionava na rua da Pedreira, a educação feminina obedecia aos mesmos moldes. Enquanto aos meninos se ensinava, além da formação de bons costumes ("primeiro, e principal cuidado de um mestre"), a gramática latina e portuguesa, língua francesa e inglesa, e primeiras letras, "com perfeição, método fácil, e breve", em sala separada as meninas tinham uma mestra de primeiras letras, e, se quisessem, de gramática portuguesa, e outra para ensinar a coser, bordar, e cortar todas as roupas de senhoras $\left(1815, \mathrm{n}^{\circ} 50\right)$.

Passando agora à educação masculina, vemos, através dos avisos da Gazeta, que havia um leque de oportunidades maior do que no caso da educação feminina. A maior parte das instituições tambem ensinava simplesmente as primeiras letras, ou seja, a ler, escrever e contar, mas a variedade era grande nas disciplinas oferecidas pelas aulas particulares. Além do Catecismo, da Religião, da Moral, da Política e Civilidade Cristã, da Filosofia Racional e Moral, da Gramática Latina, ensinava-se: Matemáticas puras e Matemáticas aplicadas à Geografia, à Marinha, à Arquitetura, ao Comércio, Escrituração dobrada, Aritmética, Álgebra, Trigonometria retilínea e esférica, Astronomia, Pilotage, Geografia (que tambem aparece com a designação de Geografia natural), Teoria Geral do Universo, Hidrografia, Desenho e Figura, Pintura, História portuguesa, Língua inglesa, francesa, alemã, italiana, toscana e sienese, Belas Letras, Gramática portuguesa, Retórica, Ortografia, Estenografia portuguesa.

E comum ler-se nas histórias da cultura portuguesa e brasileira que o ensino era, no início do século XIX, essencialmente livresco, teológico, divorciado enfim da realidade social. Ao analisarmos contudo os anúncios de aulas na Gazeta do Rio de Janeiro, tivemos a impressão exatamente contrária: numa sociedade intensamente preocupada com as atividades comerciais, os professores procuravam atender esses interesses. Em primeiro lugar a grande abundância de aulas de inglês e francês mostra que havia mais procura de línguas vivas do que de latim, por exemplo. Se a demanda de professores de francês e inglês era grande, tambem o era a concorrência entre eles e por isso a publicidade insistia na superioridade do método empregado, como acontece neste anúncio que apresentamos como exemplo:

"O P. A. Ribis, professor das línguas francesa e inglesa, oferece os seus serviços aqueles que desejam aprender estas línguas tão geralmente faladas na Europa. Ele tem adotado para o seu curso de instrução o método novo de $M$. Dufief, autor do Dicionário e Gramática francesa nos Estados Unidos da Améri- 
ca. O sucesso deste método para ensinar prontamente as línguas tem adquirido ao autor uma reputação justamente merecida..." $\left(1817, \mathrm{n}^{\circ} 50\right)$.

Além do ensino das línguas mais úteis ao Comércio, havia quem ensinasse disciplinas pouco comuns mas consideradas de igual utilidade:

\begin{abstract}
"Quem quiser aprender estenografia portuguesa, ou arte de escrever com a rapidez da palavra, convenção adotada em todos os idiomas, e que pode ter muitas vantagens; pode dirigir-se à rua da Cadeia, $\mathrm{n}^{\mathrm{0}} 51$, da parte esquerda, das 3 horas da tarde por diante" (1817, $\left.\mathrm{n}^{\circ} 50\right)$.
\end{abstract}

O professor de primeiras letras, Jordão Reinaldo, chegado de Lisboa em 1811, anunciava um colégio, onde se ensinaria tudo o que era necessário para formar "um hábil negociante e um útil cidadão" (1811, $\mathrm{n}^{\text {\% }}$ 62). João Lourenço Toole, professor de inglês, ensinava Aritmética e Escrituração dobrada (5), matérias estas de interesse comercial, do mesmo modo que "as Matemáticas aplicadas ao Comércio", tantas vezes anunciadas.

E evidente que ao lado destas aulas e cursos que atendiam uma procura por parte de caixeiros e guarda-livros e que deste modo se adatavam às necessidades mais prementes da sociedade carioca, havia outros cursos mais tradicionais, geralmente ministrados por eclesiásticos, que coexistiam com os primeiros: ensinava-se Gramática latina, Filosofia racional e moral, Política (6) e Civilidade cristã. Digamos que aos clérigos cabia a educação propriamente dita, ou seja a transmissão de normas, de regras de bem viver na sociedade, juntamente com um verniz de Latim e Filosofia. Havia por exemplo um clérigo que se oferecia como mestre de educação e de civilização, "quer na vida doméstica, na militar, do comércio, e das letras, tanto civis, como eclesiásticas", o que assenta no pressuposto de que as normas, as re-

(5) . - Segundo José da Silva Lisboa, em Princípios do Direito Mercantil, vários eram os livros necessários aos homens de negócio: o Borrador, o Diário, o Livro de Faturas, o Livro copiador de cartas, o Livro de contas em partidas simples, ou dobradas, o Livro de contas correntes e finalmente o Livro de letras de câmbio, de risco, de apólices de seguro. (Tratado VII, cap. IX). Compreende-se assim que nos anúncios apareça com tanta freqüência a escrituração dobrada.

(6). - Há aqui uma questão semântica a esclarecer: quando nos surgem nos anúncios lições de Politica, este termo está empregado num sentido próximo de Polícia, ou seja, como explica Morais e Silva no seu Dicionário, "cultura, adorno, urbanidade dos cidadãos, no falar, no termo, na boa maneira". 
gras, são específicas a cada área de atividade dentro da sociedade.

Em 1816 os negociantes do Rio de Janeiro, para comemorarem a elevação do Brasil a reino, ofereceram-se para formar um capital cujo rendimento seria perpetuamente aplicado para estabelecimentos que promovessem a instrução nacional. Perante esta oferta o Príncipe Regente determinou que os novos etsabelecimentos fossem erigidos na Corte, a fim de que os descendentes dos beneméritos negociantes deles pudessem usufruir. (Reino - 5 de março de 1816). Além disso as cadeiras científicas já existentes seriam reunidas às que se viessem a criar, "em ordem a completar um Instituto Acadêmico" que englobasse não só o ensino das ciências, mas ao mesmo tempo "o das Belas Artes e o de sua aplicação à Indústria", pois só assim contribuía de fato para a civilização e prosperidade das nações. Ignoramos o que resultou efetivamente desta oferta dos negociantes, pois nada encontramos na documentação que provasse a criação imediata de algum estabelecimento com tais fundos.

Além da existência de cursos e aulas, criados por iniciativa estatal ou por iniciativa privada, temos de levar em conta ainda, como outra forma de transmissão da cultura, as "leituras" ou conferências. Daniel Gardner, "Doutor em Medicina, Membro das Sociedades Matemática e Filosófica de Londres", anunciou em 1810, na Gazeta do Rio de Janeiro, as suas leituras sobre Química e Filosofia Natural. Foi escolhido o horário das 6 das tarde, talvez para conseguir um auditório mais numeroso, pois a essa hora todas as repartições públicas estavam já fechadas. Para atrair a assistência, o Dr. Gardner referia-se no anúncio aos "aparatos químicos", assaz dispendiosos, que se destinavam a completar as conferências, e tambem ao compêndio que 'se estava publicando e que poderia ser obtido logo na primeira leitura (1810, no 51). Tais conferências devem ter tido sucesso, pois em 1811 o Dr. Gardner voltou a anunciar na Gazeta, avisando que o seu laboratório químico estaria aberto todas as quintas-feiras à tarde, para repetir as leituras que ele tivera a honra de fazer na presença do Regente e da Família Real (1811, no 60). Ao mesmo tempo comunicou o preço da inscrição, 640 reis, mas depois resolveu que a primeira leitura seria gratuita. O local onde se realizaram estas Conferências foi o Seminário de S. Joaquim, onde tambem Silvestre Pinheiro Fereira fez umas preleções filosóficas (7).

(7). - Sobre estas preleções ver a nossa tese de doutoramento: "Metodologia da história do pensamento. Análise concreta: o pensamento de Silvestre Pinheiro Ferreira (1796-1846) ", Universidade de São Paulo, 1967. 